\title{
Accuracy of young male drivers' self-assessments of driving skill
}

\author{
Martinussen, Laila Marianne; Møller, Mette; Prato, Carlo Giacomo
}

Published in:

Transportation Research. Part F: Traffic Psychology and Behaviour

Link to article, DOI:

10.1016/j.trf.2017.03.001

Publication date:

2017

Document Version

Peer reviewed version

Link back to DTU Orbit

Citation (APA):

Martinussen, L. M., Møller, M., \& Prato, C. G. (2017). Accuracy of young male drivers' self-assessments of driving skill. Transportation Research. Part F: Traffic Psychology and Behaviour, 46(A), 228-235.

https://doi.org/10.1016/j.trf.2017.03.001

\section{General rights}

Copyright and moral rights for the publications made accessible in the public portal are retained by the authors and/or other copyright owners and it is a condition of accessing publications that users recognise and abide by the legal requirements associated with these rights.

- Users may download and print one copy of any publication from the public portal for the purpose of private study or research.

- You may not further distribute the material or use it for any profit-making activity or commercial gain

- You may freely distribute the URL identifying the publication in the public portal

If you believe that this document breaches copyright please contact us providing details, and we will remove access to the work immediately and investigate your claim 


\title{
Accuracy of Young Male Drivers' Self-assessments of Driving Skill
}

\author{
Laila M. Martinussen ${ }^{\mathrm{a}}$, Mette Møller ${ }^{\mathrm{a}}$, Carlo G. Prato ${ }^{\mathrm{b}}$ \\ ${ }^{a}$ DTU Management, Diplomvej, Building 372, DK-2800 Kgs. Lyngby, Denmark \\ ${ }^{\mathrm{b} S}$ School of Civil Engineering, The University of Queensland, 4072 Brisbane, Queensland,
}

Australia 


\section{ABSTRACT}

Accurate self-assessment of skill is important because it creates an appropriate level of confidence and hence behaviour. Inaccurate self-assessment of driving ability has been linked to reckless driving and accidents. Inaccurate self-assessment of driving skills may be a contributing factor to the over-representation of young male drivers in accident statistics. Most previous research on self-assessment of driving skills did not compare self-reported skills to objectively measured driving skills, so the aims of this study were: 1) to test the accuracy of young male drivers' self-assessments of specific driving skills by comparing them with performance in a driving simulator; 2) to test whether self-assessment accuracy varied with driving skill, driving experience and sensation-seeking propensity. We found that young male drivers' selfassessments were inconsistent with their driving performance, and that this inconsistency varied with driving skill, driving experience and sensation-seeking propensity. Groups with particularly inaccurate self-assessments are at high risk, because of their relative lack of skill, high mileage and sensation-seeking propensity. Self-assessments of hazard prediction and detection skills were particularly inaccurate. Understanding self-assessments of driving skill is crucial, but further studies are needed to allow preventive policies and interventions to take factors affecting self-assessments into account.

Keywords: Self-assessed driving skills; driving skills; driving experience; sensation seeking; driving simulator, young male drivers 


\section{Introduction}

Self-assessment requires an individual to assess his or her own skills and this selfgenerated feedback can contribute to confidence in one’s skills. The higher one's self-assessed skill the more likely one is to feel competent in a particular domain thereby influencing behaviour (Bandura, 1997). Accurate self-assessment is important because it creates an appropriate level of confidence in one’s skill (Coronado-Aliegro, 2006). Underestimation may lead to unnecessary, self-imposed restrictions on activity whereas overestimation may lead individuals to participate in activities which are beyond their competence (Bandura, 1997). Drivers’ self-assessments of their driving skills are not always accurate (Coronado-Aliegro, 2006; De Craen, Twisk, Hagenzieker, Elffers, \& Brookhuis, 2011; Gregersen, 1996), which may cause serious problems such as underestimation of risk, reckless driving, sensation seeking, and accidents (Gregersen, 1996; Özkan \& Lajunen, 2006; Özkan, Lajunen, Chliaoutakis, Parker, \& Summala, 2006; Sümer, Özkan, \& Lajunen, 2006). Sensation seeking is closely related to selfefficacy i.e. the belief in one's competence and capacity in a given domain (Bandura, 1994), which in turn is closely related to self-assessed competence (Coronado-Aliegro, 2006). As level of arousal is one of the means persons assess their self-efficacy through, high sensation seekers have the opportunity to develop positive perceptions of their self-efficacy by successful performance in the thrilling situations they expose themselves to. Thus, the relation between selfassessed skills and behaviour is the result of a continuous and dynamic interplay of mutual influence leading appropriate self-assessment to be of key importance for safe driving behaviour.

It is well-known that young male drivers are over-represented in accident statistics, and continue to be so despite road safety improvements, educational interventions and targeted policies (Hansen \& Jensen, 2012; OECD, 2006; Twisk \& Stacey, 2007). Inaccurate self- 
assessment of driving skill may be a contributing factor in this as young drivers have a tendency to overestimate their driving skill (De Craen et al., 2011) and there is evidence from other fields that the accuracy of self-assessments vary according to skill level, implying variability within sub-groups of people (Ehrlinger, Johnson, Banner, Dunning, \& Kruger, 2008; Haun, Zeringue, Leach, \& Foley, 2000; Kruger \& Dunning, 1999). Specifically, it has been shown that less skilled individuals are less accurate in their self-assessments than highly skilled individuals (Ehrlinger et al., 2008). In relation to driving, drivers who passed their driving test made more accurate self-assessments of driving skill than drivers who failed the test (Mynttinen, Sundström, Vissers, Koivukoski, Hakuli, \& Keskinen, 2009) and similarly, young drivers who had just passed their driving test had high confidence in their driving skill (Grayson \& Elliott, 2004).

Research on self-assessments of driving skill has usually considered drivers as a homogeneous group, but given that driving behaviour and skill are known to vary according to individual factors such as gender, age, driving experience, personality etc. (Lajunen, Corry, Summala, \& Hartley, 1998; Lucidi, Giannini, Sgalla, Mallia, Devoto, \& Reichmann, 2010; Özkan \& Lajunen, 2006; Rimmö 2002; Zuckerman, 2007) it is important to establish whether such factors also influence the accuracy of self-assessments. This study contributes to this by investigating the influence of driving skill, driving experience and sensation-seeking propensity on the accuracy of driving self-assessments.

Many previous studies have found that drivers tend to overestimate their driving skills (for an overview, see Sundström, 2008). The majority of these studies used self-report measures in which drivers were asked to compare their driving skills to the skills of the average driver. This method of assessing driving skill has been criticised because it does not compare subjective self-assessments of skill with an objective measure of driving skill and therefore it has been 
suggested that self-reports should be validated through comparison with objectively measured driving performance (Sundström, 2008).

One approach to validation is to compare a driving license examiner's assessment of a driver's skills to his or her self-assessment (De Craen et al., 2011; Mynttinen et al., 2009). Using this method Mynttinen et al. (2009) found that about $40 \%$ of the drivers overestimated their skills, and De Craen et al. (2011) found that young drivers overestimated their driving skills. A potential problem with this method is that it relies on an expert's subjective assessment of driving skills and is thus subject to human flaws and inter-rater variability. Another way is to validate based on data from naturalistic driving, but safety issues make this problematic. Similarly, it is impossible to expose all participants to an identical driving scenario. Using a driving simulator to measure driving performance addresses these problems (Boyle \& Lee, 2010): use of a virtual, controlled experimental setting ensures that drivers' skills and behaviour can be assessed safely and objectively. The driving simulator also enables the researcher to measure performance of specific driving skills for comparison with the driver's self-assessment of the same driving skills.

The main aim of this study was to test the accuracy of young male drivers' selfassessments of driving skills using a driving simulator. A second aim was to examine whether self-assessment accuracy varied with driving skill, experience or sensation-seeking propensity. Based on the above, we hypothesized that driving skill level, driving experience and sensation seeking would affect self-assessment accuracy. Specifically, we hypothesized inaccurate selfassessment among less skilled drivers and drivers with little experience, and we expected that thigh sensation seekers would have high confidence when self-assessing their skills. The study was conducted at the Technical University of Denmark. 


\section{Method}

\subsection{Participants}

The participants were male students from the Technical University of Denmark.

Participants were aged between 18 and 31 years old and were recruited on campus or via a Facebook site. Informed consent was obtained by all participants. The sample characteristics are given in Table 1. All participants had a driving license for cars (type B).

\section{Table 1}

Sample characteristics

$N$

Age

Mean

SD

Years with driving license

Mean

SD

Weekly mileage (km)

Mean

SD
31

23.10

2.54

5.16

3.30

107.61

130.94

\subsection{Equipment and materials}

Driving skills were measured via a driving simulator. The Driving Skill Inventory (DSI; Lajunen \& Summala, 1995) was used to collect self-assessments of driving skills and the Brief Sensation Seeking Scale (BSSS; Hoyle, Stephenson, Palmgreen, Lorch, \& Donohew, 2002) was used to assess sensation-seeking propensity.

\subsubsection{Driving simulator}

The experiment was conducted using a fixed-base driving simulator with a $180^{\circ}$ visual field with rear and side view mirrors. The simulator software used was ‘ScanEr Studio’. Six different scenarios were scripted in ScanEr Studio in order to measure driving skills specified in the DSI (see Tables 2 and 4). The six scenarios were set in a city environment, a representation 
of an urban Copenhagen area or a rural environment, featuring a two-way rural road. A Latin Square procedure was used to counterbalance the order in which participants experienced the six scenarios. Driving data were extracted at $20 \mathrm{~Hz}$. Additionally, a qualitative measure of overtaking performance was used as the experimenter looked at each driver during the overtaking manoeuvres and, on the basis of the judgement about the safety of the situation in terms of location of the overtaking and passing gap allowed (see, e.g., Farah, Bekhor, Polus, \& Toledo, 2009; Farah, Yechiam, Bekhor, Toledo, \& Polus, 2008), evaluated the safety level of each overtaking manoeuvre.

\subsubsection{Driving Skill Inventory (DSI)}

The DSI is a questionnaire used to capture drivers' self-assessed perceptual-motor skills and safety skills. Perceptual-motor skills are technical driving skills and car-handling skills; safety skills are accident avoidance skills and careful driving practices. Perceptual-motor skills are based on information-processing and motor skills, whereas safety skills are related to attitudes and personality factors (Lajunen \& Summala, 1995). Participants were asked to report their driving skills on a five-point scale ranging from $0=$ 'Well below average' to $4=$ 'Well above average' compared to the average driver of their age and gender group. Table 4 specifies the DSI items used in this study and the behavioural indicator used to assess them in the simulator.

\subsubsection{Brief Sensation Seeking Scale (BSSS)}

The BSSS is a questionnaire used to measure sensation seeking in adolescents and young adults (Hoyle et al., 2002). Sensation-seeking propensity was assessed by asking participants to assess whether eight statements relating to liking for thrills, adventure seeking, social 


\section{disinhibition, susceptibility to boredom and experience seeking were true of them or not (see}

\section{Table 3).}

\section{Table 2}

Description of the scenarios

\begin{tabular}{cll}
\hline Scenario & Environment & Scenario description \\
1 & City & $\begin{array}{l}\text { As the driver approaches a parked bus (and other parked cars) a pedestrian runs out } \\
\text { from behind the front of the bus into the street }\end{array}$ \\
3 & Rural & $\begin{array}{l}\text { A car approaches from an adjacent road on the left side and merges in front of the } \\
\text { driver. The car accelerates and decelerates in front of the driver }\end{array}$ \\
4 & Rural & $\begin{array}{l}\text { A moped is travelling slowly ahead of the driver } \\
\text { A car is approaching rapidly on the right side of the driver at a crossing where the } \\
\text { driver has green and the approaching car red; the approaching car stops just before } \\
\text { moving into the driver's lane }\end{array}$ \\
6 & City & $\begin{array}{l}\text { A car is approaching rapidly on the right side in front of the driver and crosses the } \\
\text { road when the driver has green and the crossing car red }\end{array}$
\end{tabular}

Note. The Danish drive on the right-hand side of the road.

Table 3

The Brief Sensation Seeking Scale (BSSS)

\begin{tabular}{ll}
\hline $\begin{array}{l}\text { Item } \\
\text { number }\end{array}$ & Items \\
\hline 1 & I would like to explore strange places \\
2 & I get restless when I spend too much time at home \\
3 & I like to do things that scare me \\
4 & I like wild parties \\
5 & I would like to go on a journey without any pre-planned routes or time schedule \\
6 & I prefer friends who are unpredictable in an exciting way \\
7 & I would like to try bungee-jumping
\end{tabular}


Note. Item number relates to numbering in Hoyle et al. (2002).

\subsection{Procedure}

The simulator task consisted of one introductory drive and six experimental drives (see Table 4). For all participants the task began with an introductory drive in a rural environment to allow them to familiarise themselves with the simulator. Before the experimental drives participants were instructed to drive normally and remain on the main road. All participants completed three experimental drives, had a pause, and then completed the remaining three experimental drives (see Table 2). After completing the driving simulation task participants filled out the BSSS. Half of the participants completed the DSI before the simulator task and the remainder completed the DSI one week after the simulator task. This procedure was used to control for potential order effects (Ozby, 2009).

\subsection{Data preparation and analysis}

\subsubsection{Data preparation}

All behavioural measures are given in Table 4. All behavioural data were re-coded using a five-point scale corresponding to the DSI scale $(0=$ 'Well below average' to $4=$ 'Well above average'). For continuous variables the scale was based on the percentile distribution of the performance of the sample, thus the least skilled participant and the most skilled participant were used as thresholds. Data on overtaking were categorical and were therefore mapped as follows: 0 = overtook in dangerous circumstances (equivalent to 'well below average'); 2 = did not overtake ('about average'); 4 = overtook safely ('well above average').

\subsubsection{Data analysis}


Cronbach’s Alpha analysis was performed to test the psychometric properties of the DSI (see Table 4). To test whether self-assessments of driving skill varied according to objectively measured driving performance, driving experience or sensation-seeking propensity the sample was divided into two groups with respect to each factor. Participants were assigned to the highor low-driving skill group on the basis of whether their total score on the behavioural measures was above or below the median for the sample. A similar procedure was used to create low- and high-experience groups (on the basis of weekly mileage) and high- and low-sensation seeking groups (on the basis of BSSS score). Accuracy of self-assessed driving skills was tested in the whole sample, as well as related to driving skill, driving experience, and sensation seeking using paired-sample non-parametric Wilcoxon Signed Ranks t-tests (see Table 5 and 6).

\section{Results}

The psychometric properties of the DSI can be seen in Table 4. The paired sample Wilcoxon Signed Rank t-test showed that there were discrepancy between self-assessed skills and objective behavioural measures in the simulator. Most pronounced was the discrepancy in hazard prediction, hazard detection and maintain a safe distance (see Table 5).

\section{Table 4}

The scenarios with the DSI items measured in each and corresponding behavioural measures

\begin{tabular}{|c|c|c|c|c|}
\hline \multirow[t]{3}{*}{ Scenario } & \multicolumn{3}{|c|}{ DSI } & \multirow[t]{3}{*}{ Behavioural indicator } \\
\hline & & & Skill type & \\
\hline & $\begin{array}{l}\text { Item } \\
\text { number }\end{array}$ & Item description & $\begin{array}{l}\text { (Alpha value P-M: } \\
\text { 0.79; S: 0.65) }\end{array}$ & \\
\hline \multirow[t]{2}{*}{1} & 7 & $\begin{array}{l}\text { Prediction of } \\
\text { situation ahead }\end{array}$ & $\begin{array}{l}\text { P-M: Hazard } \\
\text { prediction: }\end{array}$ & $\begin{array}{l}\text { Speed at event time (ET) }-5 \text { s minus } \\
\text { speed at ET -1s }\end{array}$ \\
\hline & 11 & $\begin{array}{l}\text { Performance in } \\
\text { critical situations }\end{array}$ & P-M: Hazard detection & $\begin{array}{l}\text { Latency to braking (after start of the } \\
\text { event) }\end{array}$ \\
\hline
\end{tabular}




\begin{tabular}{ccccl}
\hline 2 & 23 & $\begin{array}{c}\text { Avoiding } \\
\text { unnecessary risk }\end{array}$ & S: Hazard prediction & Speed at ET -5s minus speed at ET -1s \\
\hline 3 & 11 & Fast reactions & P-M: Hazard detection & Latency to braking \\
\hline 4 & 11 & Fast reactions & P-M: Hazard detection & Latency to braking \\
\hline 5 & 20 & Overtaking & P-M: Overtaking: & $\begin{array}{l}\text { Whether the driver overtakes, and if so } \\
\text { whether it is done safely }\end{array}$ \\
\cline { 2 - 5 } & 18 & $\begin{array}{c}\text { Keeping sufficient } \\
\text { distance }\end{array}$ & $\begin{array}{c}\text { S: maintenance of safe } \\
\text { gap to car in front }\end{array}$ & Minimum time to collision \\
\hline 6 & \multicolumn{1}{c}{$\begin{array}{c}\text { Overtaking } \\
\text { 18 }\end{array}$} & $\begin{array}{c}\text { Keeping sufficient } \\
\text { distance }\end{array}$ & $\begin{array}{c}\text { S: maintenance of safe } \\
\text { gap to car in front }\end{array}$ & Minimum time to collision \\
\hline
\end{tabular}

Note. $\mathrm{P}-\mathrm{M}=$ Perceptual-motor skills; $\mathrm{S}$ = Safety skills.

Table 5

Comparison of driving performance and self-assessed driving skill in the whole sample

\begin{tabular}{|c|c|}
\hline Scenario & Behavioural measure \\
\hline 1 & Hazard prediction \\
\hline Z & $-2.73^{b}$ \\
\hline \multirow[t]{2}{*}{ p-value } & $0.006^{* *}$ \\
\hline & Hazard detection \\
\hline Z & $-2.52^{\mathrm{b}}$ \\
\hline p-value & $0.012 * *$ \\
\hline 2 & Hazard prediction \\
\hline Z & $-1.45^{\mathrm{b}}$ \\
\hline p-value & 0.148 \\
\hline 3 & Hazard detection \\
\hline Z & $-3.17^{b}$ \\
\hline p-value & $0.002 * *$ \\
\hline 4 & Hazard detection \\
\hline Z & $-2.72^{\mathrm{b}}$ \\
\hline
\end{tabular}




\begin{tabular}{cc} 
p-value & $0.006^{* *}$ \\
\hline $\mathbf{5}$ & Overtaking \\
$\mathrm{Z}$ & $-1.18^{\mathrm{b}}$ \\
$\mathrm{p}$-value & 0.236 \\
& Safe gap to car in front \\
$\mathrm{Z}$ & $-2.22^{\mathrm{b}}$ \\
$\mathrm{p}$-value & $0.027^{* *}$ \\
\hline $\mathbf{6}$ & Overtaking \\
$\mathrm{Z}$ & $-0.047^{\mathrm{b}}$ \\
$\mathrm{p}$-value & 0.963 \\
& Safe gap to car in front \\
$\mathrm{Z}$ & $-1.80^{\mathrm{b}}$ \\
$\mathrm{p}$-value & 0.073 \\
\hline
\end{tabular}

Notes. ${ }^{\mathrm{b}}$ negative difference performance and self-assessment

The paired-sample Wilcoxon Signed Rank t-tests showed that the discrepancy between self-assessed skill and objectively measured performance was more pronounced in more low skilled drivers, experienced drivers and drivers with a greater propensity to sensation seeking (see Table 6). Self-assessments of hazard prediction, hazard detection and maintain a safe distance were particularly inaccurate in low-skill drivers (see Table 6). More experienced drivers were most inaccurate in their self-assessments of hazard prediction, hazard detection and overtaking skills, whereas less experienced drivers were most inaccurate in their self-assessments of hazard detection skill and ability to maintain a safe gap to the car in front (see Table 6). Drivers with high sensation-seeking propensity were inaccurate in their self-assessments of hazard prediction, hazard detection and ability to maintain a safe gap to the car in front. Drivers 
with low sensation-seeking propensity were inaccurate in their self-assessments of hazard prediction and hazard detection (see Table 6).

\section{Table 6}

Comparison of driving performance and self-assessed driving skill in the high and low driving skill, -, driving experience, - and sensation seeking groups

\begin{tabular}{|c|c|c|c|c|c|c|}
\hline \multirow[t]{2}{*}{ Scenario } & \multicolumn{2}{|c|}{ Driving skill } & \multicolumn{2}{|c|}{ Driving experience } & \multicolumn{2}{|c|}{ Sensation seeking } \\
\hline & \multicolumn{6}{|c|}{ Behavioural measure: Hazard prediction } \\
\hline 1 & Low & High & Low & High & Low & High \\
\hline $\mathrm{Z}$ & $-1.754^{\mathrm{C}}$ & $-2.116^{\mathrm{C}}$ & $-1.138^{\mathrm{C}}$ & $-2.848^{\mathrm{C}}$ & $-2.366^{\mathrm{c}}$ & $-1.327^{c}$ \\
\hline \multirow[t]{2}{*}{ p-value } & 0.079 & $0.034 *$ & 0.255 & $0.004^{*}$ & $0.018 *$ & 0.185 \\
\hline & \multicolumn{6}{|c|}{ Behavioural measure: Hazard detection } \\
\hline $\mathrm{Z}$ & Low & High & Low & High & Low & High \\
\hline \multirow[t]{2}{*}{ p-value } & $-2.622^{\mathrm{C}}$ & $-0.535^{\mathrm{c}}$ & $-1.976^{\mathrm{c}}$ & $-1.561^{\mathrm{C}}$ & $-1.069^{c}$ & $-2.303^{c}$ \\
\hline & $0.009 *$ & 0.593 & $0.048 *$ & 0.119 & 0.285 & $0.021 *$ \\
\hline
\end{tabular}

Behavioural measure: Hazard prediction

\begin{tabular}{ccc|cc|cc}
\hline 2 & Low & High & Low & High & Low & High \\
$Z$ & $-2.098^{\mathrm{c}}$ & $-0.366^{\mathrm{c}}$ & $-0.292^{\mathrm{c}}$ & $-1.897^{\mathrm{c}}$ & $-1.051^{\mathrm{b}}$ & $-2.631^{\mathrm{c}}$ \\
p-value & $0.036^{*}$ & 0.714 & 0.770 & 0.058 & 0.293 & $0.009^{*}$
\end{tabular}

Behavioural measure: Hazard detection

\begin{tabular}{ccc|cc|cc}
\hline 3 & Low & High & Low & High & Low & High \\
$\mathrm{Z}$ & $-3.019^{\mathrm{c}}$ & $-1.259^{\mathrm{c}}$ & $-2.201^{\mathrm{c}}$ & $-2.565^{\mathrm{c}}$ & $-2.506^{\mathrm{c}}$ & $-1.964^{\mathrm{c}}$ \\
p-value & $0.003^{*}$ & 0.208 & $0.028^{*}$ & $0.010^{*}$ & $0.012^{*}$ & $0.050^{*}$
\end{tabular}

Behavioural measure: Hazard detection

\begin{tabular}{ccc|cc|cc}
\hline 4 & Low & High & Low & High & Low & High \\
$\mathrm{Z}$ & $-3.443^{\mathrm{c}}$ & $-0.288^{\mathrm{b}}$ & $-1.787^{\mathrm{c}}$ & $-2.095^{\mathrm{c}}$ & $-0.792^{\mathrm{c}}$ & $-2.754^{\mathrm{c}}$ \\
p-value & $0.001^{*}$ & 0.773 & 0.074 & $0.036^{*}$ & 0.428 & $0.006^{*}$
\end{tabular}


Behavioural measure: Overtaking

\begin{tabular}{ccc|cc|crc}
\hline $\mathbf{5}$ & Low & High & Low & High & Low & High \\
$\mathrm{Z}$ & $-1.029^{\mathrm{c}}$ & $-0.660^{\mathrm{c}}$ & $-0.112^{\mathrm{c}}$ & $-2.157^{\mathrm{c}}$ & $-0.322^{\mathrm{b}}$ & $-0.364^{\mathrm{c}}$ \\
p-value & 0.304 & 0.509 & 0.911 & $0.031^{*}$ & 0.747 & 0.716
\end{tabular}

Behavioural measure: Safe gap to car in front

\begin{tabular}{ccc|cc|cc} 
& Low & High & Low & High & Low & High \\
Z & $-2.587^{c}$ & $-0.482^{c}$ & $-2.517^{c}$ & $-0.073^{b}$ & $-0.395^{c}$ & $-2.732^{c}$ \\
p-value & $0.010^{*}$ & 0.630 & $0.012^{*}$ & 0.942 & 0.693 & $0.006^{*}$
\end{tabular}

Behavioural measure: Overtaking

\begin{tabular}{ccc|cc|cc}
\hline $\mathbf{6}$ & Low & High & Low & High & Low & High \\
$\mathrm{Z}$ & $-0.226^{\mathrm{b}}$ & $-0.660^{\mathrm{c}}$ & $-1.024^{\mathrm{b}}$ & $-1.730^{\mathrm{c}}$ & $-1.024^{\mathrm{b}}$ & $-1.730^{\mathrm{c}}$ \\
p-value & 0.821 & 0.509 & 0.306 & 0.084 & 0.306 & 0.084
\end{tabular}

Behavioural measure: Safety gap to car in front

\begin{tabular}{ccc|cc|cc} 
& Low & High & Low & High & Low & High \\
Z & $-1.165^{\mathrm{c}}$ & $-1.267^{\mathrm{c}}$ & $-2.110^{\mathrm{c}}$ & $-0.090^{\mathrm{b}}$ & $-0.247^{\mathrm{c}}$ & $-2.178^{\mathrm{c}}$ \\
$\mathrm{p}$ & 0.244 & 0.205 & $0.035^{*}$ & 0.928 & 0.805 & $0.029^{*}$ \\
\hline
\end{tabular}

Notes. ${ }^{\text {c }}$ positive difference between performance and self-assessment; ${ }^{\mathrm{b}}$ negative difference performance and selfassessment

\section{Discussion}

The primary aim of this study was to test how accurate young male drivers are when they self-assess specific driving skills. The second aim was to test whether the accuracy of selfassessments varied according to driving skill, driving experience and sensation-seeking propensity. The results indicated that young male drivers’ self-assessments of their driving skills are inconsistent with their driving performance, mostly pronounced for hazard prediction, - and detection skills. The results also indicated that the inconsistency varies with driving skill, driving 
experience and sensation-seeking propensity. In line with results in other fields (e.g. Dunning, Heath \& Suls, 2004; Ehrlinger et al., 2008) we found that self-assessments of driving skill were more inaccurate in less skilled drivers than high skilled drivers, also more experienced drivers, and drivers with high sensation-seeking propensity were inaccurate in their self-assessment. Moreover self-assessments were particularly inaccurate with respect to hazard prediction, hazard detection and ability to maintain a safe gap to the car in front. Because of the small sample size the results should be read with care. Nonetheless, the results suggest that sub-groups of young male drivers' self-assessment seem to vary and that this should be further explored, as developing preventive policies and interventions may benefit from taking into account factors that affect the accuracy of self-assessments of skill, such as experience, sensation-seeking propensity and skill level.

Overestimation of driving skills among young (and novice) drivers have been found before (OECD - ECMT, 2006). However, the relation seems to be more complex as some studies report that young drivers do not differ from for example older drivers in self-assessment, or that the overconfidence is not seen in all driving situations (Mayhew \& Simpson, 1995). Studies also show that the confidence depends on the method (average versus peer comparison) used to assess young drivers' self-assessment (De Craen et al., 2011). De Craen et al. (2011) also show that young drivers are more confident in their self-assessment than experts who indicate their opinion about the participants' performance. It should be noted that the current study presents specific driving skill measures, unlike previous studies (including De Craen et al., 2011) that presented general driving skill measures.

It has been suggested that self-assessment is based on a top-down approach in which preconceived beliefs about one's skills are given great weight with the result that less skilled drivers 
mistakenly assess their driving skills as good (Dunning, Johnson, Ehrlinger, \& Kruger, 2003). The inaccuracy of less skilled performers' self-assessments is compounded by the fact that the skills needed to perform proficiently are similar to those needed to evaluate one's own performance. Unskilled performers are unable to recognise the discrepancy between skilled and unskilled performance, leading to inaccurate self-assessment (Kruger \& Dunning, 1999). The finding that the self-assessments of less skilled drivers were more inaccurate than those of more skilled drivers is consistent with this account of self-assessment. Similarly, Mynttinen et al. (2009) found that self-assessments of driving skill were more accurate among learner drivers who passed their driving test than those who failed. The results for more skilled drivers were surprising, as in other domains it has been shown that highly skilled performers assess their own skills accurately but tend to overestimate the skills of others and thus underestimate their own relative skill (Kruger \& Dunning, 1999).

It seems likely that the feedback drivers receive whilst driving contributes to the inaccuracy of less skilled drivers' self-assessments. Involvement in an accident might be considered the ultimate form of negative feedback on driving skill, but since accidents are rare given the amount of traffic (3.4 deaths per 1 billion vehicle km in Denmark in 2012, OECD/ITF, 2014), less skilled drivers' overestimation of their competence may be reinforced by the fact that they have not been involved in an accident. A similar logic might also contribute to the inaccuracy of more experienced drivers' self-assessments, as they too are unlikely to be involved in an accident in spite of their driving frequency (Elvik, 2010).

In the context of road safety, the inaccuracy of the self-assessments of drivers with higher sensation-seeking propensity is of particular importance as it suggests that drivers with a high sensation-seeking propensity poses a dual risk as they have a high tolerance for risk and 
overestimate their own driving skill. Reports that high sensation seekers are more likely to be involved in accidents than low sensation seekers (Elander, West, \& French, 1993; Gregersen, 1996) are consistent with this argument. Sensation seekers seek out risky situations (Zuckerman, 1978) and the thrill they experience in such situations further reduces their ability to self-assess. Bandura $(1986,1994)$ suggested that individuals could mistakenly interpret stress as a sign that they lack skill, which might lead to a lack of confidence when engaging in an activity. In contrast, thrill (arousal) might mistakenly be interpreted as a sign of skill, leading to high confidence in one’s capability (Bandura, 1986, 1994). In other words sensation seekers may interpret the thrill which they experience in risky situations as an indication of high skill. Future research on self-assessments of driving skill could profitably explore the relationship between sensation seeking, driving behaviour and self-assessment of driving skill in more depth by larger sample sizes and also by measuring other variables related to sensation seeking such as testosterone and cortisol levels.

Self-assessments of hazard prediction and detection were found to be particularly inaccurate in the present sample of young male drivers. This may be explained by a combination of lack of skill and insufficient cognitive development. Perception and prediction of hazards are related to perception of risk and self-assessed ability to cope with the hazard, and young drivers have shortcomings in both these areas (Deery, 1999; McKenna \& Crick, 1991). Skilful performance is guided by higher-order self-regulatory skills including general skills for identifying task demands, constructing and evaluating different courses of action, setting appropriate goals, constructing appropriate incentives to enable one to sustain one's effort in the face of setbacks, and coping with stress and negative thoughts (Bandura, 2006). These skills are relevant to skilful driving performance (Hatakka, Keskinen, Gregersen, Glad, \& Hernetkoski, 
2002). Both perception and prediction of hazards and self-assessment of driving skill are complex tasks which require these higher-order skills, but the neurobiological systems which support higher-order self-regulatory cognitive processes such as evaluation, decision making and impulse control are not fully developed until about 25 years (Giedd, 2010; Reyna \& Farley, 2006), making $87.2 \%$ of the present sample subjected. Young drivers’ neurocognitive immaturity may explain why their self-assessments were particularly inaccurate in relation to hazard perception and detection.

Limitations to the study should be acknowledged. Firstly, and as addressed before, the sample size is small and this suggests caution towards the generalization of the results. However, the findings from the study are robust (see Stuart, Ord, \& Arnold, 2009) and the sample was chosen as homogeneous (young male drivers) to reduce the effect of possible confounders (e.g., gender, age). Although the sample was recruited on campus at the university and was not representative of the population, the findings provide a clear indication of the accuracy of selfassessment and provide a robust basis for further discussion on the subject.

Secondly, when using a simulator the issue of ecological validity will always emerge. The skills measured in a simulator might be different from the actual driving skills. To overcome this limitation, the results could be verified by data collected in a natural driving setting, but this would generate an ethical issue because of the possible risk issues related to measuring driving skills in a natural driving setting. Driving simulators bares positive solutions to many issues when measuring driving behaviours and skills, despite never being completely comparable to real driving.

Another related issue is the validity of the scales used. Participants might have various perceptions of what an average driver skill is, making it difficult to compare across the sample. 
This issue was overcome by informing the participants to compare against their own gender and age group i.e. compare against the same standards, however the group with which they compare, and consider average, may nevertheless vary. One cannot be sure what participants actually do compare with the same average group nor have the same perception of what average is, as some may consider average something negative rather than neutral (Groeger, 2000).

\section{Conclusion}

Because of the small sample size the results and conclusions of this study need to be read with care and future studies with larger sample sizes might be pursued in order to support and extend the present results. Nevertheless, the results indicate that the accuracy of self-assessment of driving skills among young male drivers vary, particularly with regard to perception and prediction of hazards. Measures to improve drivers’ self assessment are relevant, but further studies are needed to allow preventive policies and interventions to take factors affecting selfassessments of skill such as skill level, experience, and sensation-seeking propensity into account.

\section{Acknowledgement}

Financial support from by the Danish Council for Strategic Research (Det Strategiske Forskningsråd) is greatly appreciated. We are grateful to Víctor Checa Albarrán for his help with data collection, and to Kenneth Christensen, Allan Olsen and Liva Abele for help with scripting scenarios. Finally we are thankful for insightful remarks provided during the review process. 


\section{References}

Bandura, A. (1986). Social foundations of thought and action: A social cognitive theory. Englewood Cliffs, NJ: Prentice Hall.

Bandura, A. (1994). Regulative function of perceived self-efficacy. Hillsdale, NJ: Lawrence Erlbaum Associates.

Bandura, A. (1997). Self-efficacy. The exercise of control. New York: W. H. Freeman and Company.

Bandura, A. (2006). Guide for constructing self-efficacy scales. F. Pajares, T. Urdan (Eds.), Selfefficacy beliefs of adolescents (pp. 307-337). Information Age Publishing, Greenwich, Connecticut.

Boyle, L. N., \& Lee, J. D. (2010). Using driving simulators to assess driving safety. Accident Analysis \& Prevention, 42, 785-787.

Coronado-Aliegro, J. (2006). The effect of self-assessment on the self-efficacy of students studying Spanish as a foreign language (Unpublished doctoral dissertation). Graduate Faculty, School of Education, University of Pittsburgh.

De Craen, S., Twisk, D. A., Hagenzieker, M. P., Elffers, H., \& Brookhuis, K. A. (2011). Do young novice drivers overestimate their driving skills more than experienced drivers? Different methods lead to different conclusions. Accident Analysis \& Prevention, 43, 1660-1665.

Deery, H. A. (1999). Hazard and risk perception among young novice drivers. Journal of Safety Research, 30(4), 225-236.

Dunning, D., Heath, C., \& Suls, J.M. (2004). Flawed self-assessment. Implications for health, education and the workplace. Psychological Science in the Public Interest, 5(3), 69-106. 
Dunning, D., Johnson, K., Ehrlinger, J., \& Kruger, J. (2003). Why people fail to recognize their own incompetence. Directions in Psychological Science, 12(3), 83-87.

Ehrlinger, J., Johnson, K., Banner, M., Dunning, D., \& Kruger, J. (2008). Why the unskilled are unaware: Further explorations of (absent) self-insight among the incompetent. Organizational Behavior \& Human Decision Processes, 105(1), 98-121.

Elander, J., West, R., \& French, D. (1993). Behavioral correlates of individual differences in road traffic crash risk: an examination of methods and findings. Psychological Bulletin, $113,279-294$.

Elvik, R. (2010). Exploratory study of mechanisms by which exposure influences accident occurrence. Transportation Research Record: Journal of the Transportation Research Board, 2148, 7-82.

Farah, H., Bekhor, S., Polus, A., \& Toledo, T. (2009). A passing gap acceptance model for twolane rural highways. Transportmetrica, 5, 159-172.

Farah, H., Yechiam, E., Bekhor, S., Toledo, T., \& Polus, A. (2008). Association of risk proneness in overtaking maneuvers with impaired decision making. Transportation Research Part F, 11, 313-323.

Giedd, J. N. (2010). Adolescent brain maturation. In R. E. Tremblay, R. G. Barr, R. DeV., Peters, \& M. Bolvin (Eds.), Encyclopedia on early childhood development (pp. 1-5). Montreal, Quebec: Center of Excellence for Early Childhood Development.

Grayson, G. B., \& Elliott, M. A. (2004). The attitudes and reported behaviours of novice drivers: results from the Cohort II study. Behavioural Research in Road Safety 2004, (pp. 182193). London: DfT Publications 
Gregersen, N. P. (1996). Young drivers’ overestimation of their own skill - an experiment on their relation between training strategy and skill. Accident Analysis \& Prevention, 28(2), 243-250.

Groeger, J.A. (2000). Understanding driving - applying cognitive psychology to a complex everyday task. Psychology Press Ltd., Hove, East Sussex, UK.

Hansen, A. S. \& Jensen, C. (2012). Risiko I trafikken 2007-2010 [Risk in traffic 2007-2010]. DTU Transport, Report 4, 2012.

Hatakka, M., Keskinen, E., Gregersen, N. P., Glad, A., \& Hernetkoski, K. (2002). From control of the vehicle to personal self-control: broadening the perspectives to driver education. Transportation Research Part F, 5, 201-215.

Haun, D. E., Zeringue, A., Leach, A., \& Fole, A. (2000). Assessing the competence of specimenprocessing personnel. Laboratory Medicine, 31, 633-637.

Hoyle, R. H., Stephenson, M. T., Palmgreen, P., Lorch, E. P., \& Donohew, R. L. (2002). Reliability and validity of a brief sensation seeking scale. Personality \& Individual Differences, 32(3), 401-414.

Kruger, J., \& Dunning, D. (1999). Unskilled and unaware of it: How difficulties in recognizing one’s own incompetence lead to inflated self-assessments. Journal of Personality \& Social Psychology, 77, 1121-1134.

Lajunen, T., Corry, A., Summala, H., \& Hartley, L. (1998). Cross-cultural differences in drivers’ self-assessments of their perceptual-motor and safety skills: Australians and Finns. Personality \& Individual Differences, 24, 539-550. 
Lajunen, T., \& Summala, H. (1995). Driving experience, personality, and skill and safety-motive dimensions in drivers’ self-assessments. Personality \& Individual Differences, 19(3), 307-318.

Lucidi, F., Giannini, A. M., Sgalla, R., Mallia, L., Devoto, A., \& Reichmann, S. (2010). Young novice driver subtypes: Relationship to driving violations, errors and lapses. Accident Analysis \& Prevention, 42, 1689-1696.

Mayhew, D.R., \& Simpson, H.M. (1995). The role of driving experience. In: Implications for the Training and Licensing of New Drivers. Insurance Bureau of Canada, Toronto, Ontario.

McKenna, F. P., \& Crick, J. (1991). Experience and expertise in hazard perception. In. G.B. Grayson \& J. F. Lester (Eds.), Proceedings of the Behavioral Research in Road Safety (pp. 39-46). Crowthorne, UK: Transport and Road Research Laboratory.

Mynttinen, S., Sundström, A., Vissers, J., Koivukoski, M., Hakuli, K., \& Keskinen, E. (2009). Self-assessed driver competence among novice drivers - a comparison of driving test candidate assessments and examiner assessments in a Dutch and Finnish sample. Journal of Safety Research, 40, 301-309.

OECD/ITF, ed. (May 2014). "Road Safety Annual Report 2014" (PDF) (official report). Paris: International Traffic Safety Data and Analysis Group, International Transport Forum. OECD (2006). Young drivers - The road to safety. Transport Research Centre. ECMT. Paris: OECD Publishing.

Ozby, P. C. (2009). Methods of behavioral research (10th ed.). New York, NY: McGraw Hill.

Özkan, T., \& Lajunen, T. (2006). What causes the difference in driving between young men and women? The effects of gender roles and sex on young drivers' behavior and selfassessment of skills. Transportation Research Part F, 9, 269-277. 
Özkan, T., Lajunen, T., Chliaoutakis, J., Parker, D., \& Summala, H. (2006). Cross-cultural differences in driving skills: A comparison of six countries. Accident Analysis \& Prevention, 38, 1011-1018.

Reyna, V. F., \& Farley, F. (2006). Risk and rationality in adolescent decision making: Implications for theory, practice and public policy. Psychological Science in the Public Interest, 7, 1-44.

Rimmö, P. A. (2002). Aberrant driving behaviour: homogeneity of a four-factor structure in samples differing in age and gender. Ergonomics, 4(8), 569-582.

Stuart A., Ord, J.K., \& Arnold S. (2009). Kendall's Advanced Theory of Statistics: Volume 2AClassical Inference and the Linear Model, sixth edition. Edward Arnold Publishers Ltd., London, UK.

Sümer, N., Özkan, T., \& Lajunen, T. (2006). Asymmetric relationship between driving and safety skills. Accident Analysis \& Prevention, 38, 703-711.

Sundström, A. (2008). Self-assessment of driving skill - a review from a measurement perspective. Transportation Research Part F, 11(1), 1-9.

Twisk, D. A., \& Stacey, C. (2007). Trends in young driver risk and countermeasures in European countries. Journal of Safety Research 38, 245-257.

Zuckerman, M. (1978). Sensation seeking. In H. London, \& J. Exner (Eds.), Dimensions in personality (pp. 487-559). New York: Wiley.

Zuckerman, M. (2007). Sensation seeking and risky driving, sports, and vocations. In M. Zuckerman (Ed.), Sensation seeking and risky behavior (pp 73-106). Washington, DC: American Psychological Association. 